\title{
Managing IT as a Portfolio of Services
}

\author{
JOE PEPPARD, Cranfield School of Management
}

\begin{abstract}
Despite findings from research that the engagement and involvement of business managers and users is a critical ingredient for success with information technology, for many organisations this has proven difficult to achieve. By adopting a service orientation and managing IT as a portfolio of services, this paper illustrates that it provides a language and perspective that all employees can identify with and understand. It highlights the critical role that employees at all levels play in the delivery of services in and around the processing, provisioning and stewardship of information. The paper presents a number of frameworks and models to guide management action. The discussion also raises particular issues to consider when outsourcing. The concluding analysis is that with this required involvement of business management in the delivery of many services, the IT organisation is primarily the organisation, and not a separate function. (c) 2003 Elsevier Ltd. All rights reserved.
\end{abstract}

Keywords: IS service management, IS service delivery, IS service quality, IS service value, User satisfaction, IS organisation

Most organisations today are fundamentally dependent on their information technology systems and would quickly cease to function should the technology that underpins them ever grind to a halt. However, it is not the loss of the technology per se that would result in problems for the organisation, but the loss of the information and information handling services facilitated by the technology. These services include those that enable communication and collaboration (i.e. email, desktop videoconferencing, instant messaging), data capture (i.e. point of sale [POS] systems, Internet-based data entry systems, business intelligence, customer portals), processing (i.e. order processing, invoicing, contract management, account management), storage (i.e. data centres and databases with information about customers, inventories, assets, etc.), access (i.e. ad hoc queries, report writing), and analysis (i.e. analytics, modeling).

Information-handling services are delivered via the organisation's portfolio of applications that are implemented on its technology platform. There are also a considerable range of other services that are required in order for these information-handling services to be made available to users ${ }^{1}$. They include services around the specification of technology and applications, services concerned with design and construction of the technical infrastructure, services eliciting and analysing user requirements, services focused around user and management education, training and support, services centred around security and disaster recovery, services focused on software development, project management services, vendor and contract management services, and maintenance services. The importance of all these services for the functioning of most organisations cannot be underestimated. In most IT budgets they already account for a significant percentage of expenditure.

In the majority of organisations, responsibility for providing these services traditionally lies within the IS function, although in more recent years there has been an increasing trend for many of these services to be provided to the business from external thirdparty vendors and external service providers. That they are sourced in-house from a specialist unit is a legacy dating back to an era when a team of experts was required to maintain the mainframe computer. Back then, the focus of technology deployments was on improving efficiency through the automation of traditional clerical tasks. Over the years the role of IT in business has expanded significantly to the extent that it now often shapes business strategy. Information is also recognised as a key corporate asset. Yet the role of the IS function or how organisations structure and organise for exploiting IT has not progressed to reflect this new remit or focus.

In recognition of the changing role of IT in organisations and to highlight that the IS function does not exist merely to deliver and maintain computer systems there has been a call for it to be treated as a service provider and its processes and outputs to be managed as services. Unfortunately, this call has too often resulted in it being considered like other noncore services consumed by the business such as elec- 
tricity, water, catering or cleaning and managed as such - one only has to witness the negative results with outsourcing experienced by many organisations. However, to adopt this position is to misunderstand the role and function of these services and the implications of adopting a service orientation in the processing, provisioning and stewardship of information. Crucially, this interpretation fails to acknowledge the key role of information in the functioning of organisations today.

One of the key challenges in securing business management involvement and engagement with IT is that they are being asked to manage something that is essentially intangible, i.e. information, using something that they feel they know nothing about, i.e. technology. On top of all this, they often don't see it as being within their realm of responsibility anyway. There is also a lack of management frameworks and practices guiding action and decision-making with regard to the management of these services. This predicament is not unique to the IS function but to the management of all services provided inside an organisation by an internal function (Davis, 1993). The research that can potentially provide insights is, however, fragmented; studies have considered the IS function as a service operation (Rands, 1992), explored issues of IS and service quality (Kohlemeyer and Blanton, 2000; Pitt et al., 1995, 1998; Van Dyke et al., 1997), addressed the building of an IS service culture (Hays, 1997), and examined the impact of outsourcing IS function on service quality (Grover et al., 1996).

In this paper I explore the management of services in and around the processing, provisioning and stewardship of information. I suggest that managing IT as a portfolio of services can significantly improve the overall contribution of IT to business performance. In adopting a service orientation, it is recognised that users, managers and IS professionals all have a role to play in successfully delivering these services. While some services may be provided solely by IS professionals, many others require the active engagement and involvement of business users and managers for them to be successfully delivered. It is this involvement and engagement which is too often lacking and at the heart of the inability of IT to deliver business value.

\section{Services in and around the Processing, Provisioning and Stewardship of Information}

Before exploring the management of services involved in the processing, provisioning and stewardship of information, it is important to understand what a 'service' actually is. The few definitions of the concept of service that one can find in the literature are imprecise at best. Even in the writings of service operations management, service quality and service marketing, few scholars actually define what a service is, portraying it as something that is not manufacturing (see, for example, Schmenner, 1995). There is an implicit assumption that we all know what exactly a service is! But if we cannot define services, or fail to define them, how can we begin to manage them? Our research indicates that both business managers and IS managers do have difficulty in articulating what exactly they mean and understand by the services involved in processing, provisioning and stewardship of information - what this paper refers to as information, systems and technology (IST) services. Within any one organisation there is usually a multiplicity of views on what constitutes an IST service, presenting obvious difficulties for their management. Examples of the range and scope of IST services can be seen from the list in Box 1 .

This broad view of services is in contrast to the rather narrow perspective that is generally subscribed to by IS and business managers. The concept of IT service management that is typically encountered in the literature, has come to mean the services that are necessary to keep the computer systems running. These include configuration management, change management, release management, access control, security management and capacity management. For example, the ITIL ${ }^{2}$ IS Service Management framework has become an established platform for designing and managing IST services in an increasing number of organisations, but it focuses solely on the services around IT operations, such as security management, service reporting, availability and contingency management, release management and incident management, which are only part of the overall portfolio of IST services.

\section{Distinguishing Aspects of IST Services}

The writings in the management domains of operations, quality and service marketing provide a point of departure for exploring the concept of IST services. Drawing on these writings, together with our research, some distinguishing aspects of IST services can be highlighted:

* IST services are more or less intangible. IST services are generally something one cannot touch or feel, although they may be associated with something physical, such as the provision of information through a computer screen or personal digital assistant (PDA). While an IST service may have a predominantly physical outcome, for example the delivery and installation of a PC or the provision of a cable for a network connection, the service itself includes the process of delivery and installation as well as the cable. There are other services that may be totally intangible, such as advice and support from a help desk, IT training, contingency 


\section{Box 1 Examples of Services Involved in the Processing, Provisioning and Stewardship of Information}

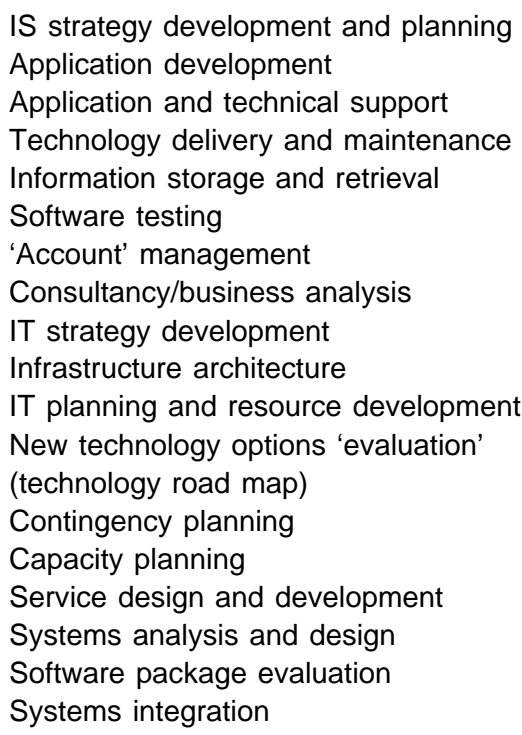

Systems implementation

Programming and software development/acquisition

Project management

Managing relationships with vendors

Training

Application maintenance and change control

First line user support/problem resolution

Advice ('service' centre, 'Help desk')

Security/access control

Information 'procurement' (external sources, etc.)

Installing PCs, servers, and cables

Maintaining the networks

Maintenance of hardware

Upgrading software

Supplier and contracts management

Change management planning, consultancy, systems design, or upgrading server software. The information handling services provided via applications are also intangible but they do require a physical platform in order to exist.

* There can be high involvement of people in the delivery process. For many IST services there can be a significant involvement of people in their successful delivery. This involvement extends not just to those delivering the service but also to those users of the service. For example, developing software depends on users accurately defining their requirements as well as on the skill and competence of the development team in interpreting these requirements. Users may have to work through instructions relayed to them over the telephone from a help desk in order to resolve their problem. This involvement of people has implications for recruiting and training of IS staff that will be involved in the delivery of the service. While people can be unpredictable in their behavior, the design of the delivery process can influence the degree of discretion that both parties have within this process. In addition, the expectations of both those involved in the delivery of the service as well as those availing of the service can have a strong bearing on the quality and level of satisfaction of the service.

The implication of the involvement of people means that IST services are therefore the result of role interactions rather than 'things', with both provider and recipient having a role to play in the delivery process and ultimately its outcome. For some services, like support or training, the delivery process can be just as important as the actual end result. This, therefore, has implications not just for the behavior of IS staff but also for the 'culture' of the IS function. In a similar way, it also has profound impacts for outsourcing of many ser- vices; clients are not just buying a result but also making an implicit commitment to be involved in the delivery process. However, this aspect of outsourcing is generally neglected.

* Many IST services are at least to some extent produced and consumed simultaneously. For example, support from a helpdesk is generally provided and utilised immediately. The consequence of this is that 'bad' service cannot be saved by a quality control check at the end of the delivery process, as is the situation with many manufacturing processes. Poor delivery, often referred to as a 'bad experience' can leave the recipient frustrated and create an impression that can impact any assessment of satisfaction and influence their perception of IS's ability to deliver long after the experience.

* Inability to place in inventory. Unlike physical products, services cannot be placed in inventory and called off during busy periods. For instance, a help desk assistant idle for 20 minutes, is 20 minutes that is forever lost; similarly, a project manager with time between projects is also time lost. The management of capacity is therefore of crucial importance in the provision of many services and ultimately in managing costs. Some services, like maintenance for example, can be scheduled to take up the idle time of IS staff between projects.

* Many IST services cannot readily be displayed, demonstrated or communicated. It is a fact that many IST services cannot be examined prior to commitment to purchase or avail of, as one might a product with physical attributes. You can test drive a car and can expect consistency in what the product does but how can one 'test drive' an IST service? Information handling services are generally more predictable in their behaviour - once a user understands the email system and how to navigate the graphical user interface (GUI), for example, sending and receiving email is generally consistent 
over time. This is because the service delivery process has been clearly defined and automated and performance metrics can be defined and expressed as SLAs. However, performance criteria such as response times can be influenced by the availability of bandwidth and network load.

It should also be noted that IST services can be either visible or invisible from the perspective of the user of the service, which can have implications for their management. The direct provision of a service such as a help desk can be highly visible when the service is being availed of, although relatively invisible when not used. Maintaining the network, upgrading hardware, backing-up servers, security, incident discovery and resolution, systems administration or contingency management are generally invisible to the user and considered as back office activities. That is, until there are problems. Consequently, business executives may be reluctant to pay for such services and this is an issue addressed later in the paper.

\section{IST Service Categories}

Research and practice from service industries highlights the inappropriateness of treating service as a homogeneous concept - different services can exhibit different attributes, raise different issues and require managing in different ways. Unfortunately, we have found that many organisations treat all IST services in a similar fashion and manage them in similar ways. Having examined a wide range of IST services, our research suggests that they can be categorised under one of four headings: applications services, operational services, value-enabling services and infrastructure services.

Applications services: refer to those services delivered via software applications. These services are derived from the 'information handling' abilities of technology, and include information processing services, information sharing services, information storage services and information access services. Application services directly impact the performance of business processes with process designs or components of processes imbedded in software applications. While organisations have traditionally custom developed or purchased 'packaged' application software, today, application service providers (ASPs) deliver a variety of information handling services direct to the desktop or other device via both the fixed and wireless Internet for a rental fee.

Operational services: are those services that relate to assembling and operating the core IT environment. Such services include installation of hardware and software, maintaining the communications network and servers, upgrading software, configuration management, change management, trouble-shooting hardware and software problems, and running the data centre.
Value-enabling services: are services that are provided to enhance the value of information assets or identify opportunities provided by IT to better manage information. Examples include, IS strategy development, systems analysis, systems design, requirements gathering, infrastructure architecture, network design, user support (including helpdesk), purchasing, vendor management, and consulting.

Infrastructure services: are those services that are derived directly from the infrastructure investment, essentially the technology itself. In fact, these 'services' are better described as technical capabilities rather than services in the true sense of the word ${ }^{3}$. These IT capabilities are provided by the hardware, software and communications infrastructure of the company. On their own, they provide little direct value to the company - without them, however, application will have nothing to run on. These services are derived from the technology itself, and include capacity (bandwidth and storage), connectivity, scalability and flexibility. Security can also be included in this category. Investments in infrastructure services can be hard to justify using traditional financial criteria as their value is often in the options they provide for the future.

There is a high level of dependency between these service categories. Email, for example, is an application service, providing the facility to communicate and move information around the organisation or with others outside the organisational boundary. Associated operational services include keeping the network up and running, maintaining directories, actioning any security requirements. Providing user support via the helpdesk is a value-enabling service. Similarly, a 'firewall' is an application service, providing a security layer for the email system. Determining and planning security requirements is a value-enabling service, installing a firewall or upgrading this software is an operational service. Certain infrastructure capabilities will be required to ensure that these applications actually function. Some organisations define infrastructure services to include e-mail and the desktop. We would argue that while the desktop, if it only includes the operating systems, can be considered as an infrastructure service, all information handling services are application services and should be managed as such.

Figure 1 shows the relationship between the four categories of IST services and how they support business operations. It illustrates that both the application services and value-enabling services interface directly with users and they can be considered as 'front-office' services. Operational and infrastructure services are 'back-office' services, usually carried out outside the users 'line of vision' and perhaps without their direct knowledge. Such services are often only recognised when something goes wrong, or there is a problem, such as a server crashing or a security breach. Problems reported at a help desk (a value- 


\section{Business strategy and operations}

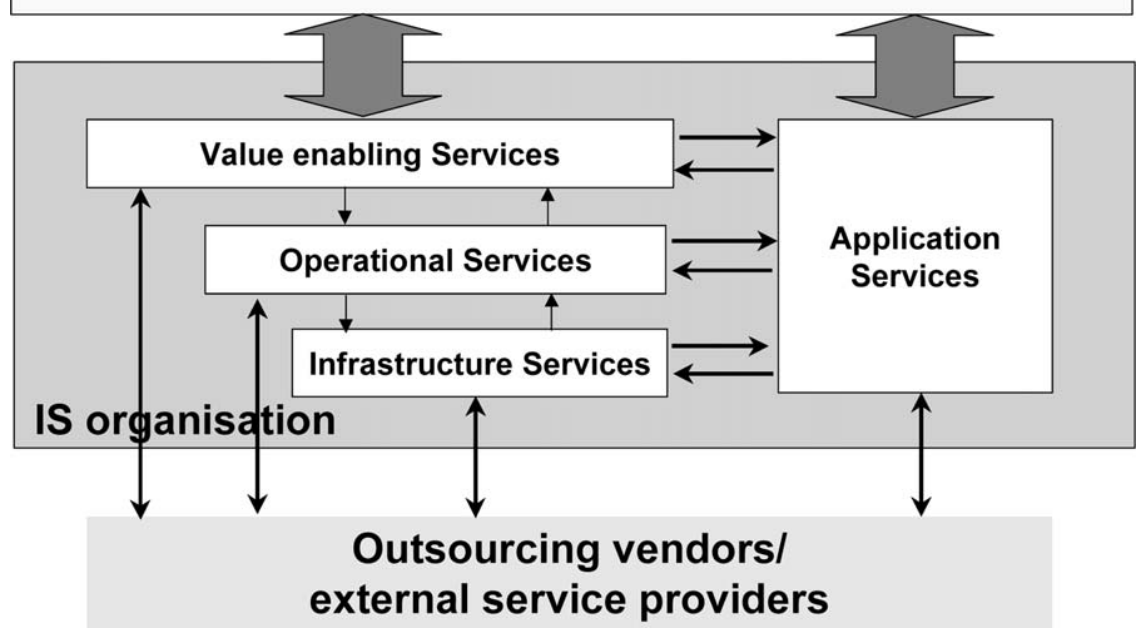

Figure 1 Relationships Between the Four IST Service Categories and Business Strategy and Operations

enabling service) may be escalated to a network team for resolution (an operational service). Value enabling, operational and infrastructure services all exist to support the application services. The figure also illustrates that IST services can be provided by an internal in-house IS function or aspects outsourced to third-party providers.

There are, however, a number of value-enabling services with the following outcomes that should never be outsourced to third parties. These are (Willcocks and Lacity, 1998):

* tracking, assessing and interpreting changing IT capabilities and relating them to organisational needs;

* working with business management to define the information-handling requirements over time;

* identifying appropriate ways to use the external marketplace, specify and manage IS/IT sourcing;

* monitoring and managing contractual relations.

\section{Assessing the Value of IST Services}

It seems reasonable to assume that investments are made in IST services in order to deliver some value to the organisation. As already noted, despite the large sums of money involved, the majority of organisations treat IST services as an administrative expense or cost and not as an investment, and manage them as such. This situation is partly due to the intangible nature of services, making it difficult to appraise the value the business derives from any spend. Consequently, most organisations do not even attempt to quantify their value. It is usually only application services that require financial justification before any spend is incurred. Spending on other IST services is seen as an overhead and therefore a sunk cost to be minimised. Findings from our research suggests that there is a way to begin to consider the 'value' from IST services and engage management in a meaningful dialogue.

To assess the value of IST services it is often helpful to make a distinction between the user or community of users who use the services and the benefits which they receive and the benefits derived by the organisation as a whole. Benefits of a service do not necessarily flow from the user to the organisation, and a trade-off generally has to be made in assessing value. For example, a user may be very satisfied with receiving immediate support from a help desk (indeed, this may be an expectation, but that's another issue), yet the cost of providing such a prompt service when compared to the benefits which the organisation receives from such immediate response can mean that it is a loss-making investment. Similarly, providing Internet access to all employees, even those who do not require it in the performance of their day-to-day duties, may increase their overall job satisfaction but have little consequential business benefits.

We are therefore faced with a dilemma. On the one hand, users are looking to get their work done as efficiently and effectively as possible, minimising any disruption. While on the other, the organisation is looking to optimise the value of the investment it makes in IST services. Consequently, in exploring value in the context of IST services three concepts must be considered: utility, benefit, and value itself.

As noted in the previous section, many IST services do not provide direct value to an organisation. Rather, they may facilitate the achievement of value. Drawing on the concept of utility from economics, 
this term is used to refer to the benefit which a user or community of users attaches to a particular service, perhaps based on the usefulness of the service to them in the performance of their jobs. In essence, it represents the satisfaction a user receives in availing of a particular service 4 . This utility can arise through problem reduction or resolution, the avoidance of disbenefits, through increased reliability or perhaps through the fact that having the service available may be a comfort factor providing an emotional benefit. It has been suggested that customer utility and satisfaction are better understood by recognising that: users have goals, leading to goal based satisfaction; users use the service and derive consequential based satisfaction; and users have desires about service attributes which lead to attribute based satisfaction (Woodruff, 1997).

Utility, however, should not be confused with value. The term value is used to capture the overall benefits from the service which the organisation receives from investing in that service. This value has two components: organisational benefits and user utility. Thus value is assessed based on the extent to which it supports the organisation in the achievement of business objectives and the utility that users receive when availing of the service. For example, the activities of systems analysis and design themselves do not provide any direct benefits to the organisation. The benefit is through the resultant information handling services provided by the application resulting from the specification developed during analysis and design.

For applications, the benefit is generally derived through business change or innovation supported or shaped by the application, for example performing work at lower cost, quicker or more accurately. Projects are the mechanisms through which applications and requisite changes are delivered. Traditionally, investment proposals will include these benefits in any return on investment (ROI) calculations. A benefit to an organisation might also be through opportunity realisation. Applications themselves can also cause changes in the organisation, which may or may not be beneficial. The value from operational and infrastructure service categories is more difficult to calculate. This is because they provide no direct utility to users. It is probably one reason why it can be difficult to justify investments in infrastructure users see no direct impact. The utility provided to users from application and value-enabling services is a mixture of soft and intangible benefits as well as more concrete outcomes such as improvement in productivity. Figure 2 maps utility and benefit against the four service categories, illustrating the nature and source of possible benefits.

The overall value $(v)$ which is derived from an investment in a service is therefore a function of the utility to the user $(u)$ and the benefit to the organisation $(b)$, such that it can be written as

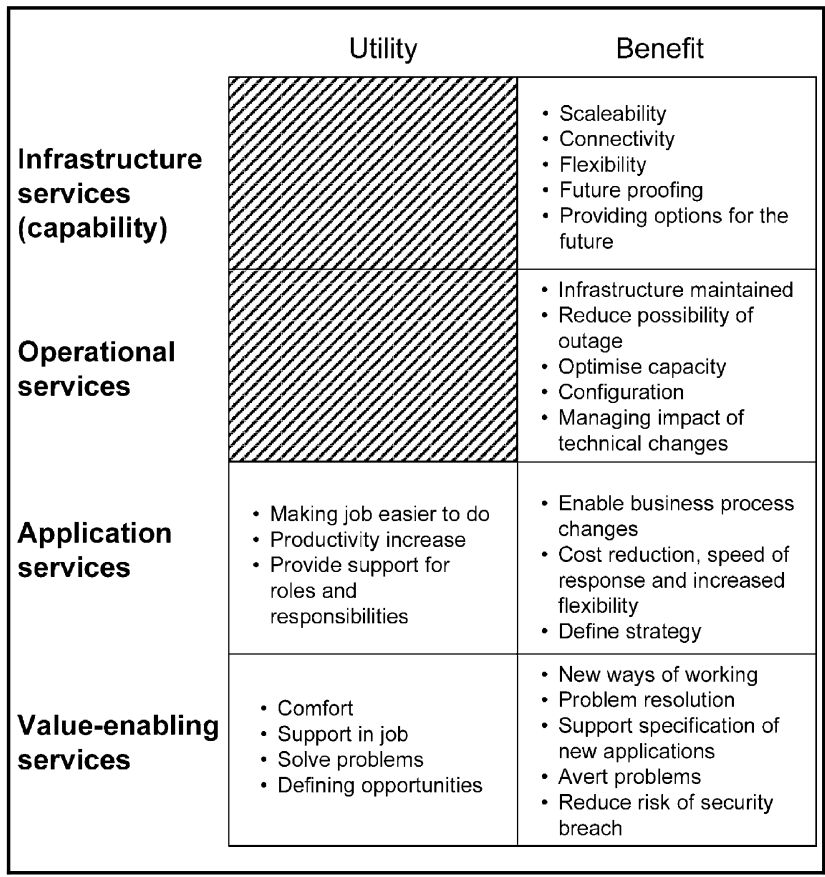

Figure 2 Example Sources of Value from IST Services

$$
v=f(u, b)
$$

This function can be mapped on a graph, as illustrated in Figure 3, to provide a representation of the trade-offs that are usually required between personal utility and benefit in assessing overall value to the business. The top curve maps utility against cost. It highlights that when more of a service is made available, utility generally increases. However, the marginal increase in utility is likely to decline beyond a certain level of spend. The lower curve maps organisational benefits against cost and illustrates that the more an organisation spends on a particular service, benefits increase up to a point and then start to decline. Figure 4 brings both curves together, mapping utility and benefit on one axis and cost on the other. For a service such as help desk, as more resources are made available to support the user, the

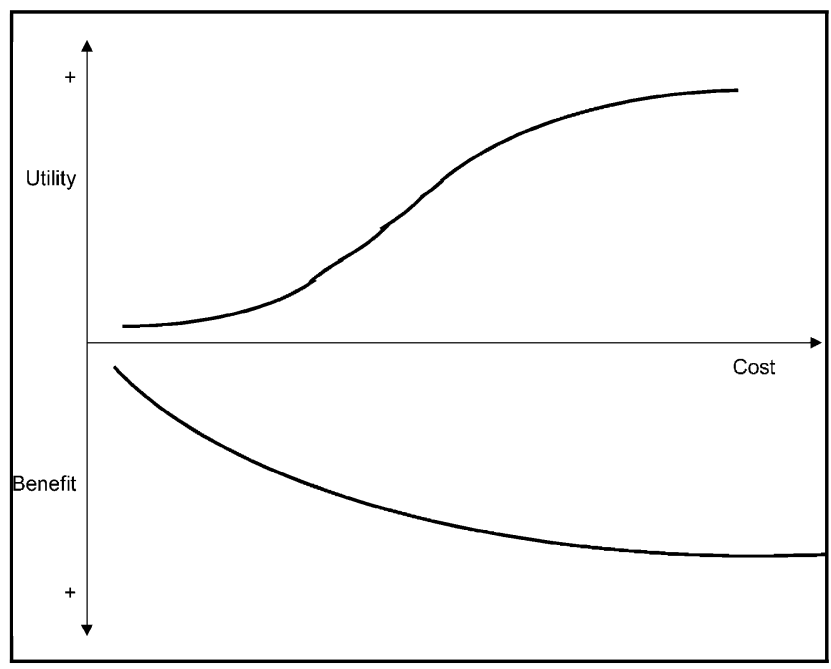

Figure 3 Cost, Utility and Benefit Trade-off Curves 


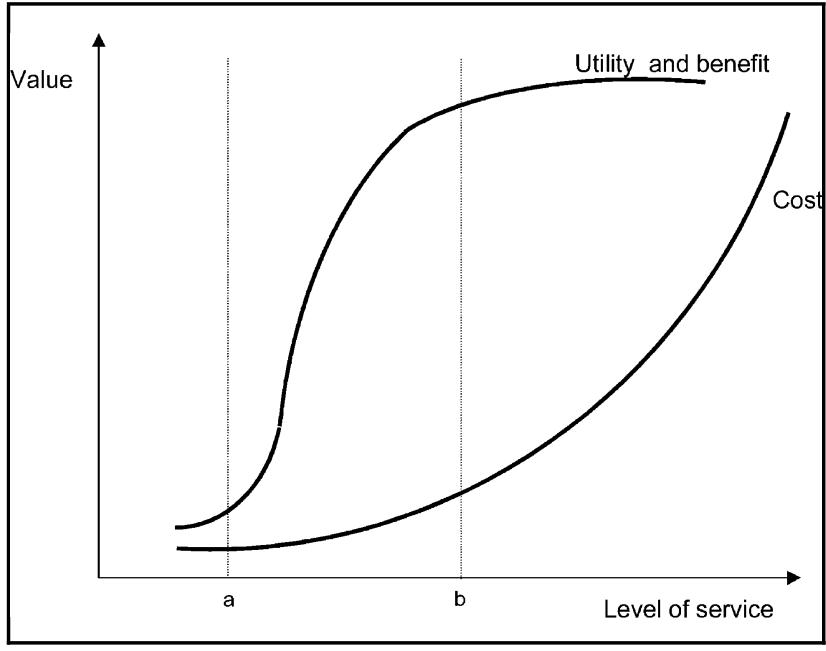

Figure 4 Cost, Value, and Level of IST Services

cost of providing the service increases, while one would also expect that the utility increases although this is unlikely to be linear relationship. From an organisation perspective, while some level of user support via a help desk is likely to deliver some level of organisational benefits, there is, however, likely to be diminishing returns beyond a certain level of investment where the cost of providing the service exceeds the benefits that can be expected (i.e. the overall value).

To determine the optimum level of spend for any service 'marginal analysis' will need to be conducted. Figure 4 shows that point ' $b$ ', for that level of spend, delivers greater value to the business that a spend a point ' $a$ '. However, beyond ' $b$ ', the difference between benefits and costs decrease. Collecting the necessary figures for such calculations can be difficult. However, it is often the richness of conversation that occurs between business and IT management around the curves that is most valuable rather than the actual figures. We have found that even using the logic of cost, value and level of service in a management dialogue can be very valuable in getting business management to understand the tradeoffs involved. Of course, the profile of the curves will vary in every organisation as they are likely to have different cost bases and begin from different positions.

This, however, is not the complete story. In the delivery of many IST services the empathy which the provider has with the user can also be a critical determinant of user utility. So, there could be a situation where a smaller help desk, staffed by friendly service staff is perceived as providing a better service to users than a larger desk with unfriendly staff. The expectations of users are also involved in determining utility. If expectations of users are low, a given level of investment can result in a higher level of utility than if expectations are higher, where the same level of service will deliver a lower utility.
This analysis also has implications for the conduct of user satisfaction surveys. It raises the question of whether it is ever realistic or prudent to strive for users to rate a particular service very high, when the cost of achieving such a score many not ultimately deliver the requisite level of business benefit.

\section{IST Service Management}

As a concept, service management has come into widespread use in the management domain although it is generally not clearly defined what exactly service management means or actually entails. Indeed, service management is not a well-defined area or single theory of management. Rather, it is a management perspective. From an IT viewpoint, service management is a total organisational approach that makes utility of service, as perceived by the user, and the value of the service to the organisation, as the number one driving force for the operations of the IS organisation (Albrecht, 1988).

IST service management has a number of fundamental objectives (adapted from Gronroos, 1986).

* To understand the utility end users receive by consuming or using the service and how these contribute to the value which the organisation derives, that is, to understand how utility is perceived in user relationships, and how it changes over time;

* To understand how the IS organisation (personnel, technology and physical resources, and applications) and users will be able to produce and deliver this utility and value;

* To understand how the IS organisation should be developed and managed so that the intended utility and value is achieved; and

* To make the IS organisation operation so that the utility and value are achieved and the objectives of all parties involved are met.

For the IT director and executive IT management, some of the peculiarities of services in an IT context also need to be recognised as these can have a significant impact on user expectations and consequently the management of IST services:

* Often no competition. In many organisations, employees can only use the services provided by their internal IS organisation. This can have implications for the quality of service provided, as the impetus for excellence may be absent. However, the threat of competition from outside vendors and other third parties is having a significant impact and internal IS functions are waking up to the fact that if they fail to meet users needs or are perceived as being expensive that users may look outside for future service provision. Benchmarking can provide a vehicle for assessing the 
performance of the IS organisation in relation to the delivery of many IST services.

* There is a general expectation of availability and high levels of service quality whenever required. This is particularly true when the service is provided by an in-house function and seen as a corporate good.

* Users can often be reluctant to pay for IST services or do not see the reason why they should pay for many services. This is particularly evident when the service is seen as necessary due to the perceived inadequacy of an application designed by the IS function. For example, the need for a help desk to support a complex application which has been designed and developed by the IS organisation. Charging for internal services is an emotional issue, but mechanisms may need to be introduced to ensure that it is not just availed of because it is there.

* Users lack domain knowledge. In most situations, users don't appreciate what is required in delivering the service. Providing some IST services can be complex and can have serious organisationwide implications, while they may appear as a simple activity for a user. For example, upgrading a 3000 user organisation from Windows95 to XP is a complex process, where not only is the operating system being updated but the knock-on effect to applications must be considered. We have previously noted that users also have a role to play in the successful delivery of many services and their lack of domain knowledge can impact not just the delivery process but also the ultimate outcome.

* Those who pay for the service, those who benefit from the service and those who participate in the service delivery process may be different. In essence there may be a number of different stakeholders involved in the provision of any particular service, each with different expectations and requirements. Very often it is the senior business management of organisations that negotiate and agree particular levels of service but it is the 'front-line' users who actually utilise these services in the performance of their job. In other instances, the IS organisation may negotiate with a third-party supplier for a particular level of service, while the business user actually expects another.

The IS organisation is also in an interesting middle position - they are service providers to their users, but can be customers to other suppliers of hardware, software and services. The irony is that IS staff readily adopt a customer oriented approach when acting as customers, but find it difficult to practice the same when faced with their own users. As a result, the internal adoption of customer orientation seems to be rather piecemeal, initiated often not by IS management but by pressure brought upon them from the business and users. However, these internal initiatives tend to be limited to introducing service level agreements and performance measures, with no overall service strategy.

\section{Managing the IST Service Categories}

If organisations do attempt to manage IST services they usually choose to manage them all in a homogeneous way. Our research suggests that each of the service categories should be managed in a different way. In our work with organisations we have developed a number of frameworks which have proved to be useful in guiding the management of the different categories of services. Given that infrastructure services are about providing capabilities, we have omitted them from the remainder of the discussion.

\section{Managing Operational and Value Enabling Services}

It is often helpful to view different operational and value enabling services in terms of a matrix that contrasts the degree of user involvement in their provision with the degree of customisation of the service for the user (see Figure 5). The quadrants of the matrix roughly define four reasonable distinct service delivery processes ${ }^{5}$. Closer examination reveals that each have different requirements, with different design criteria, and pose a different set of management issues to deal with.

Service processes with a high degree of user involvement will be more difficult to control and more difficult to rationalise than those with a low degree of user contact. In a high-contact system, the customer can affect the time of demand, the exact nature of the service, and the quality, or perceived quality, of the service since they are involved in the delivery process.

\section{Service Factory}

Services in this category have little or no involvement of the user in the delivery process and a low degree of customisation. Examples of IST services which are often positioned in this category are installation of PCs, maintenance of hardware and networks, security management, and asset and configuration man-

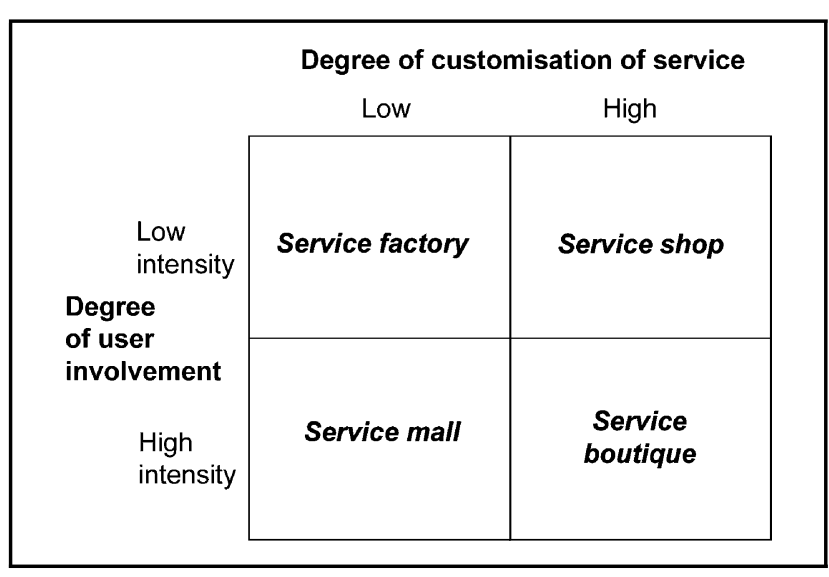

Figure 5 A Service - Process Matrix for IS Services 
agement. Such services will require relatively well defined processes. The IT services of ITIL fall within this quadrant. Key management issues include: defining service level agreements, scheduling service delivery, managing demand to avoid peaks and to promote off-peaks.

\section{Service Boutique}

Services in this quadrant are those that tend to be highly customised, process-oriented, with relatively long contact time, and where considerable judgement is applied in meeting user needs. There is also a requirement for significant user involvement in the delivery process. We have found, for example, that IS/IT strategy formulation, consulting and planning services or developing customised training programmes generally inhabit this category. Critical management issues include: hiring the right staff, training, balancing workloads, scheduling work, fighting cost increases, maintaining quality, reacting to customer intervention in process, and maintaining IT employee loyalty.

\section{Service Shop}

With the service shop, the service is customised but there is low user involvement in the delivery process. Most of the value-added is therefore provided out of sight of the user. Examples of services which can fall into this category are software development, project management, infrastructure design, vendor evaluation and contract management. Critical management issues include hiring the right staff, training, keeping abreast of changing customer needs, maintaining quality, and prioritising work.

\section{Service Mall}

Within the service mall there is a high degree of user involvement in the provision the actual service, but minimal customisation. Examples of services that are often positioned in this quadrant include application helpdesk and technical help desk. While user contact is high, the provider generally has a limited repertoire of responses to address their requests. With a low degree of customisation, a philosophy of one size fits all is generally followed. Often referred to as 'Tier 1 ' support, more complex problems are escalated for more detailed problem-solving, often by a team of specialists, perhaps operating in a service shop. Key management issues to be addressed include making service 'warm', defining service level agreements, and managing demand to avoid peaks and promote off-peaks.

With many services, there are choices regarding the appropriate delivery process to use. Training, for example can be bespoke and tailored to an audience, and thus considered a service boutique, or provided as a standard training course, in essence a service mall. If the course is delivered over the web, it is more correctly positioned as a service factory. Depending on the nature of the service, the management issues to address will be different. This frame- work also highlights the impact of different software development methodologies used in developing bespoke applications. Rapid application development (RAD) approaches and prototyping typically demand high levels of user involvement and present a different set of management issues to deal with than a traditional 'waterfall' method like SSADM (structured systems analyse and design methodology) where the involvement of users in the development is significantly reduced. On the flip side, however, high user involvement can result in a more acceptable system ultimately being developed but it does require a different set of management issues to deal with.

The service - process matrix highlights some implications for outsourcing. Outsourcing services with a high degree of user involvement and/or high level of customisation is problematic. Most organisations fail to realise that for such services, employees are intimately involved in the delivery process and this requirement cannot be ignored. Organisations may contract for a particular service, but if it is to be successfully delivered, the involvement of their employees is required. For example, many organisations often attempt to outsource IS/IT strategy development to consultants. This is not possible.

One way around this problem is to examine whether it is possible to define the delivery process as a service factory. This points to the fact that a strategic alliance type relationship with an ESP is appropriate in delivering many IST services, particularly those falling into the value-enabling category. Most operational services tend to be positioned in the service factory quadrant and are therefore more suited to direct outsourcing as the service process and outcome can be defined precisely, making the establishment of performance metrics and SLAs much easier.

\section{Managing Application Services}

The applications services portfolio is a powerful tool for understanding and managing information handling services. Illustrated in Figure 6, it classifies these information-handling services based on the contribution that they make to the achievement of the overall business success. The model indicates that all existing, planned and potential applications can be categorised based on an assessment of the current and future business importance of applications. Application services can be defined as being strategic, high potential, key operational or support, depending on their current or expected contribution to business success. Briefly, these application service categories are:

\section{Strategic application services that are critical to future business success. They create or support change in how the organisation conducts its business,}




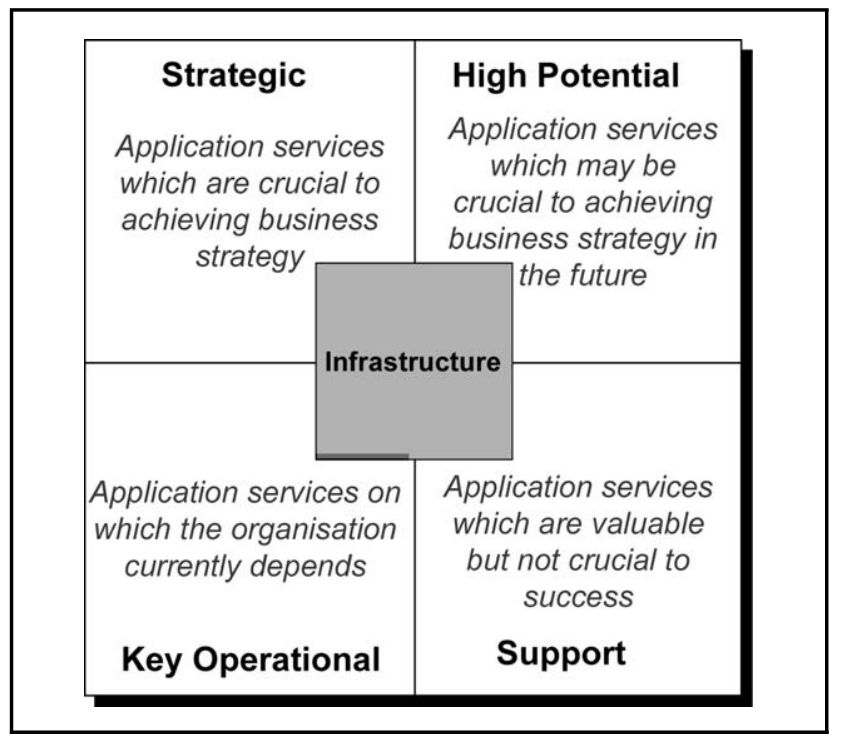

Figure 6 The Application Services Portfolio and IT Infrastructure

with the aim of providing competitive advantage. Note that whether the technology used is 'leading edge' does not indicate that the application is strategic assessment must be based on business contribution.

Key application services that sustain the operational existing business operations, helping in the avoidance of any disadvantage. In many industries, applications such as EPOS (electronic point of sale), ATMs (automated teller machines) and ERP (enterprise resource planning), become so pervasive that they have become 'mandatory' for survival in the industry and to avoid disadvantage.

Support application services that improve business efficiency and management effectiveness but, in themselves, do not sustain the business or provide any competitive advantage

High innovative information handling

potential services which may create opportunities to gain a future advantage, but are as yet unproven.

The four segments will require quite different strategies to achieve successful planning, development, implementation and operation of the applications because they fulfil different roles in the business. These are summarised in Table 1. Figure 6 also illustrates the role of the capabilities of the technical infrastructure in enabling the four types of application services.

\section{IST Service Quality}

A central aspect of the management of all IST services is attending to their quality dimensions. However, it is important not to mistake 'quality of work' for 'quality of service'. For example, the help desk may solve the printing problems of a user but it might take a week to do so. For some employees, this might be sufficient; for others it can result in invoices not being printed off and sent out to customers or outgoing correspondence being delayed and therefore resulting in a serious consequential business impact.

Over the last 20 years, the marketing and quality literatures have devoted considerable attention to the issue of service quality and delivery. Within the quality movement there are the notions of the internal customer' and 'service level agreements' or 'service guarantee' which are often devised to set parameters around the expected deliverables or outcomes. The development of IT outsourcing has seen the development of legally enforceable agreements specifying the level of service which a client can expect from a vendor.

Quality is usually assessed based on conformance to expectations, i.e. does the service meet expectations? There are two dimensions that determine whether or not the actual service meets the user expectations:

- Technical quality: this dimension is concerned with what the user receives and when.

* Emotional quality: this dimension relates to how the customer experiences the delivery of the service.

Technical quality is essentially about the specification of the service: defining what it is that the user can expect - often called the service task. For example, a service might be help and support when users have problems using an application or it can be the functionality inherence in an application. Emotional quality is generally concerned with how they want the service provider to treat them. Therefore, emotional quality is directly related to the process of service delivery and the extent of user involvement in that delivery process. Returning to the help desk example, while a user with a problem in using an application may be dealt with on immediate contact with the help desk and their problem resolved, how they are treated by the help desk staff member while their problem is being solved can influence their overall assessment of quality. Therefore, the challenge with many IST services is to recognise this emotional aspect, particularly in situations where there is a high degree of user involvement in the delivery of the service. For example, one utility company had a strategy of 'blooding' their new IT staff recruits on the help desks. While they may have had technical skills they generally did not understand the business and had little empathy with users. Consequently, users consistently rated the service as poor until this practice 
Table 1 Managing the Information Handling Services Derived from Applications

\begin{tabular}{|c|c|c|}
\hline & Sources of value & Critical requirements \\
\hline $\begin{array}{l}\text { Strategic application } \\
\text { services }\end{array}$ & $\begin{array}{l}\text { Business innovation and } \\
\text { change }\end{array}$ & $\begin{array}{l}\text { Rapid development to meet the business objectives and } \\
\text { realise benefits within the window of opportunity } \\
\text { Flexible systems that can be adapted in the future as the } \\
\text { business evolves } \\
\text { Link to an associated business initiative to sustain commitment }\end{array}$ \\
\hline $\begin{array}{l}\text { Key operational application } \\
\text { services }\end{array}$ & $\begin{array}{l}\text { Business effectiveness } \\
\text { Process rationalisation and } \\
\text { integration }\end{array}$ & $\begin{array}{l}\text { High-quality, long-life solutions and effective data management } \\
\text { Balancing costs with benefits and business risks - identifying } \\
\text { the best solution } \\
\text { Evaluation of options available by objective feasibility study }\end{array}$ \\
\hline $\begin{array}{l}\text { Support application } \\
\text { services }\end{array}$ & $\begin{array}{l}\text { Business efficiency } \\
\text { Process elimination and cost } \\
\text { reduction }\end{array}$ & $\begin{array}{l}\text { Low-cost, long-term solutions - often packaged software to } \\
\text { satisfy most needs } \\
\text { Compromise the needs to the software available } \\
\text { Objective cost/ benefit analysis to reduce financial risk and } \\
\text { then control costs carefully }\end{array}$ \\
\hline $\begin{array}{l}\text { High potential application } \\
\text { services }\end{array}$ & $\begin{array}{l}\text { Creating opportunities for } \\
\text { possible business change (or } \\
\text { proving benefits) }\end{array}$ & $\begin{array}{l}\text { Rapid evaluation of prototypes and avoid wasting effort/ } \\
\text { resources on failures } \\
\text { Understand the potential benefits (and the economics) in } \\
\text { relation to business strategy } \\
\text { Identify the best way to proceed - the next step }\end{array}$ \\
\hline
\end{tabular}

was changed. Even in organisations where experienced IT staff are used, they have generally been recruited because of their technical skills and not based on how they interact and communicate with users. Service industries have long recognised the importance of recruiting staff with the appropriate service mentality and attitude.

Value should not be confused with quality. Value is concerned with the overall benefit or gain that the organisation derives from its investment in the service. An increase in service quality, generally incurs a cost where an increase in the utility of users may not result in a corresponding increase in value to the business. Therefore a trade-off is required and, as we have seen earlier in the paper, this can be very difficult to do. It also leads one to consider how user satisfaction surveys are evaluated. For example, achieving a ' 5 ' rating (on a 1-5 scale) may indicate that users are very satisfied but the value to the business of providing the service at this level and cost may be less than providing a cheaper service.

\section{The Service Encounter}

In considering IST services, we must also address the service encounter, that is, where users and staff from the IS function come into contact and interact with each other. This may be face-to-face, as in a meeting or undertaking an interview as part as a fact-finding exercise for a systems analysis assignment. An encounter can also take place over the phone or perhaps through a corporate Intranet or by using an application. More passive primary encounters occur when the user observes the service provider providing the service, for example installing a PC. Second- ary encounters occur through conversations with employees of the IS function or with other users. Operations managers often refer to these encounters as 'moments of truth' and based on these encounters users can form a lasting impression of the IS function which can be difficult to change. Figure 7 illustrates a framework for considering the service encounter. This framework has three aspects: the service task, service standards and the service delivery system, and these have relevance for application, operational and value-enabling services.

\section{Service Task}

The service task (or 'service concept' or 'service package') states why the service exists and what the utility and value of that service are. It is a statement that conveys the essence of what the service delivers and thus provides both management and the workforce, both IS and business, with a goal to achieve. Note that the service task should always be defined with reference to the user, the organisation and its overall value to the business. Key questions to address in defining the service task are:

* What are the important elements of the services to be provided, stated in terms of results, produced for the user, for IS staff and the organisation as a whole?

* How are these elements supposed to be perceived by the target 'community of users'? By IS staff?

* What efforts does this suggest in terms of designing, delivering and marketing the service?

Answers to these questions should be as concrete as possible. 


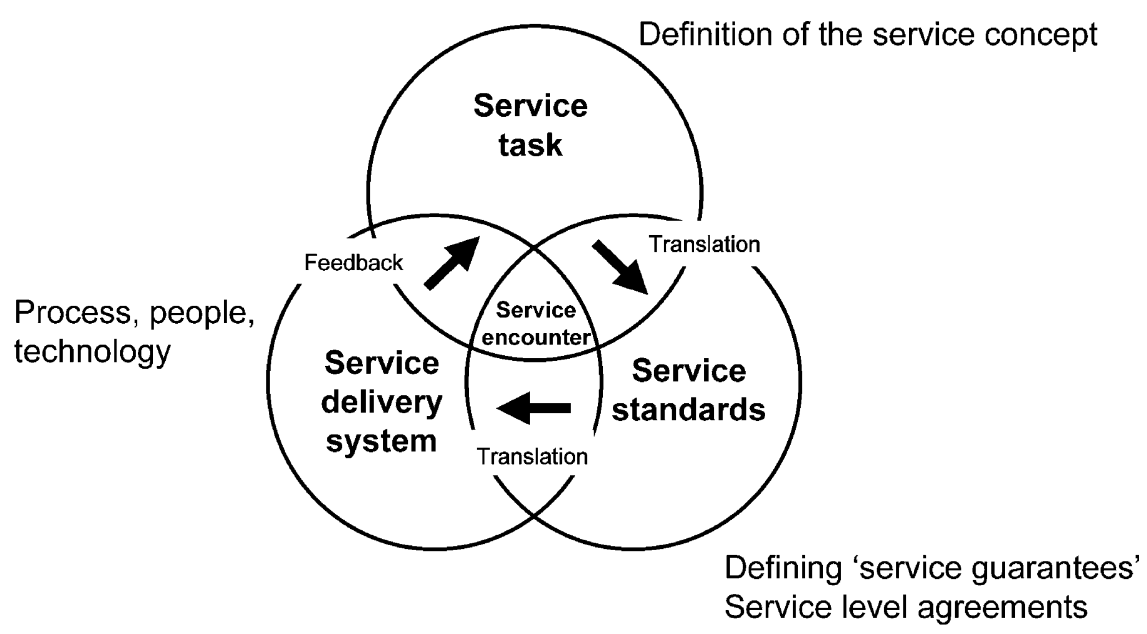

Figure 7 The Service Encounter

\section{Service Standards}

Service standards define what is effective service provision from the user perspective. The standards are the controls, the guardians of quality and cost efficiency in the IT function. Standards are measurable and typically articulated as service level agreements (SLAs). Thus, it should be possible to establish a checklist of standards and audit the service to determine how well it is being delivered against these standards.

\section{Service Delivery System}

The service delivery system specifies how the service is produced, including how it is controlled for quality, cost, and satisfaction. It essentially determines the combination and configuration of people and technology and the design of processes to be used in delivering the service and achieving the service standards. The service delivery system must therefore be synchronised with the service task and the service standards so that the service encounter remains a pleasurable one for all concerned.

We have already illustrated that with operational services and value-enabling services, the process for service delivery can be one of four types (service factory, service shop, service mall, or service boutique) and that each will require different choices to be made. Depending on the degree of customisation of the service and expectations regarding user involvement in the provision of the service, options for the design of the delivery system will vary. The design of the service delivery system will determine the role that both the provider and recipient of the service can be expected to play in the delivery of the service. Often, as it is not made explicit to users, they do not understand their role in the process and consequently this can impact the quality of service as perceived by them. If users do not engage with IS staff in the provision of services, given the design of the service delivery system, the service received can be below their expectations.

The service delivery systems for the services delivered via applications, i.e. the information-handling services, is automated, with the processes embodied in the software code. SLA are generally defined in terms of hardware and software performance. The user has little involvement in the provision of the service other than requesting it. However, the design of the user interface can influences the overall 'user experience'.

\section{Gaps in IST Service Delivery}

Much work has been done in identifying the source of 'gaps' between the user and provider that can occur in service delivery. It is perhaps easy to recognise the gap between user expectations and their perception of what is actually received. But there is research that has identified other possible reasons why gaps can occur in service delivery (Parasuraman et al., 1988) and recently some attempt has been made to extend this work into the domain of IS management (Pitt et al., 1995, 1998).

The greatest difficulty in dealing with user satisfaction is that the factors which create satisfaction will vary from user to user, and the aspect of service associated with each factor expected by each user may also be different, an issue addressed in the next section. A user's assessment of service quality will be based upon their expectations of the service to be provided. However services are assessed, users will continually expect improvement, and for it to be "perfect' on every occasion. Of course there will usually be ways to improve any aspect of the service, but at a cost. As we have already illustrated, it may not be worthwhile to expend more resources to deliver to the ultimate expectations, and therefore an assess- 
ment of whether the 'gaps' in service delivery are worth overcoming or perhaps whether action to change user expectations may be more valid.

Work by a number of researchers (Kohlemeyer and Blanton, 2000; Pitt et al., 1995, 1998) studying the nature of the gaps that can occur in IST service delivery, is very helpful in understanding why the gaps exist and to select the best options for closing them. Figure 8 shows a basic model for assessment.

This model illustrates that there are five possible gaps in service delivery. The causes of these gaps (1-5 in Figure 8) are as follows:

1. Not understanding what users expect or what contributes to utility or value due to:

* a lack analysis of user needs

* ineffective communication by either or both parties

* excessive bureaucracy in the IS function

2. Setting the wrong service standards due to:

lack of commitment to IST services by IS management

* perceptions of unfeasibility among IS staff in meeting user demands

* inadequate task definition and standardisation or inadequate resourcing to standards set

* absence of objectives for the service to achieve and/or inappropriate performance measurements

3. Under-performance of the service due to:

* role ambiguity in delivery processes, including a lack of clarity of the user's role in the service delivery process

* lack of resource availability to deliver the service

* lack of actual or perceived controls

* lack of teamwork and inappropriate resource use, or inappropriate use of the service

4. Poor communication of what the service is and can be expected to deliver due to:

* a propensity to over-promise and/or over-react to 'complaints'

* inconsistent communication across the user communities

* lack of visibility of the service process

5. Expectation versus perception gap due to:

* not understanding user requirements and reasons for them

* users not understanding the service process and the implications of their demands

* user expectations actually being impossible to satisfy!

Many IS functions conduct user satisfaction surveys, but if not well constructed the results can be misleading. Before asking a user to evaluate a service, or its more detailed attributes such as availability or responsiveness, the importance or otherwise of the service or service attributes (see below) to the user should to be understood. 'Importance' is often a surrogate for utility in terms of how dependent the user is on the service in carrying out his or her role. Evaluating services and their contribution to achieving the required performance for those who depend on it, is more important than satisfying those for whom it is

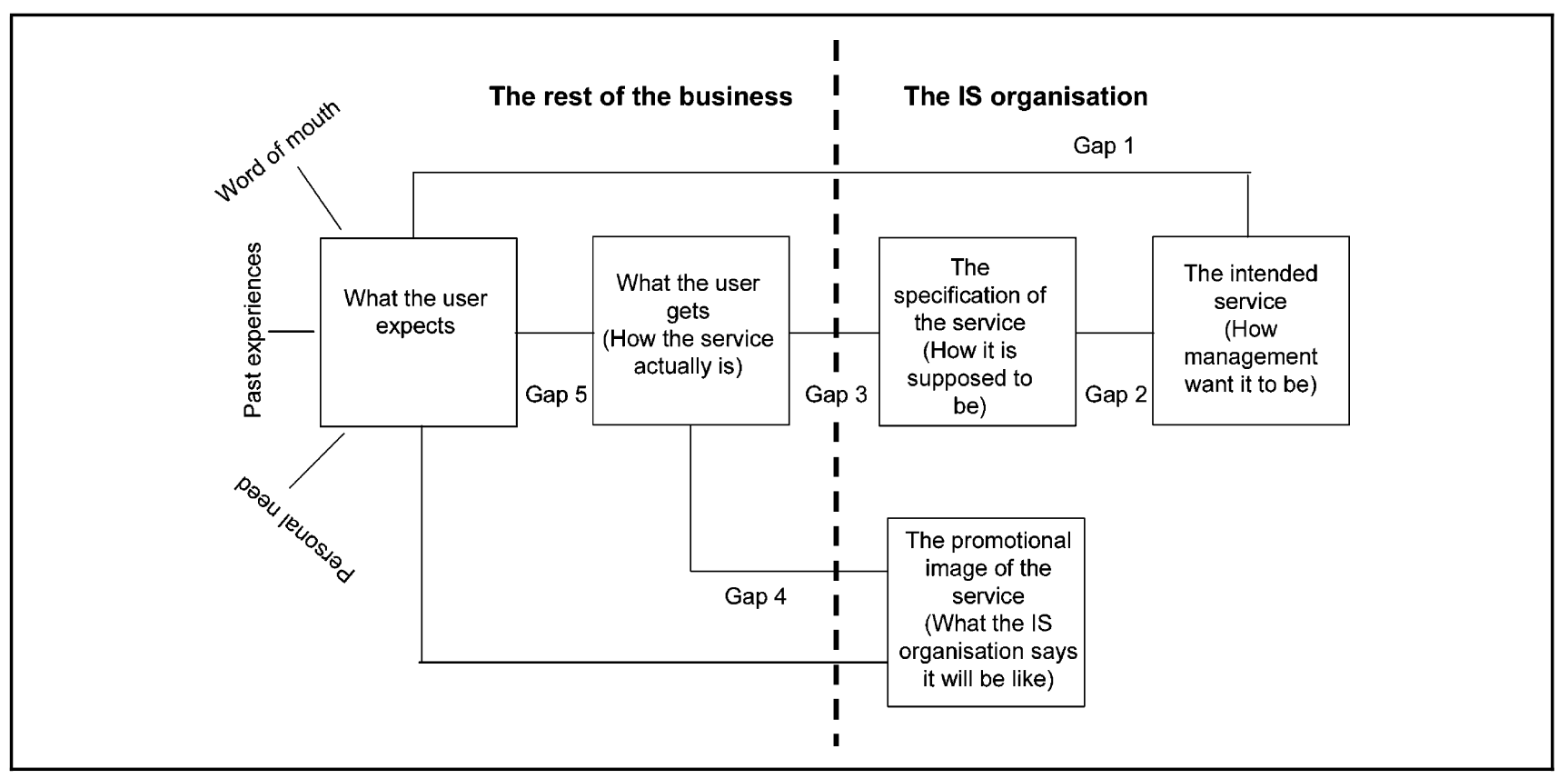

Figure 8 Sources of Gaps in IST Service Delivery 
of no great consequence. Therefore any satisfaction survey must first determine the context within which the user is judging performance (Whyte et al., 1997; Van Dyke et al., 1997).

\section{The Dimensions of IST Services}

We noted earlier the need to understand the criteria or dimensions that users utilise in determining service quality. Outside of the service task, which provides a high-level description of what the user can expect of the service, our research indicates that IST services can be 'unpacked' into a number of dimensions. This has been previously done for product quality (Garvan, 1984) and service quality (Sylvestro et al., 1992). What is important about these dimensions is that they are used by users in assessing the overall quality of services delivered. Each dimension is, in turn, influenced by factors involved in the provision of the service. So, for example, if we can identify areas of quality which users rate as problematic it should be possible to improve user assessment of quality by impacting these factors through the implementation of initiatives. These dimensions can be catagorised under the headings of value, form, level, and delivery system.

\section{The Value of the Service}

As we have already demonstrated, there are two aspects to consider in addressing the value dimension: the individual user or community of users availing themselves of the service and the business as a whole. At an individual level, we must address the utility that the user is seeking, and recognise that this may or may not be directly related to their job. For example, email services can enable an individual to communicate both intra- and inter-organisationally. At an organisation level, the benefit may be different. The cost of providing a service must therefore be matched against the utility and organisational benefit, with the overall value being a function of the utility and benefit. While users may only be interested in their personal utility in assessing the benefit to them of any service, it is important not to lose sight of the overall value to the organisation.

\section{The Form in which the Service is Available}

The form is which the service is required has two aspects:

* Nature: the definition of the expected service (i.e. service task) and how this relates to its value.

* Responsiveness: how flexible is the service? Is the service to be customisable or is it a case of 'one size fits all'? For some services, this dimension can relate to the responsiveness of the IS function to service requests.

\section{The Level of Service}

The level of the service which the user can expect has three aspects:

* Access: How easy is it for the users to gain access to the service? Can the service provider be contacted by phone? Is it available over the Internet? Can it be accessed remotely?

* Availability: Is the service available when required? Is it offered on a 24 by 7 basis?

- Reliability: Required reliability in terms of consistency. Is the service 'experience' similar every time it is delivered?

Service level agreements usually capture the form and level of service.

\section{The Delivery System by which the Service Arrives}

The delivery system defines how the process for delivering the service is designed and managed. Whether the service is defined as a service factory, service shop, service mall or service boutique usually give guidance as to the nature of the design of the delivery system. Aspects to consider in the design of the delivery system are:

* Assurance: confidence of users in IS staff and in their ability to deliver the service.

* Empathy: friendliness of IS staff and their ability to identify with the problems which the user is experiencing.

* Involvement: degree of expected user involvement in availing of the service.

Figure 9 illustrates these dimensions of IST services and maps them against the providers perspective. In the right-hand column, these dimensions are matched up with the issues that addressing these service dimensions raise from the provider perspective.

These dimensions of service quality can inform the provider perspective in the following ways:

Value We have already noted that utility is concerned with the personal benefit that the user will derive from the service. From a provider perspective, it may be that different user groups derive a different utility from the service. Therefore, this suggests that the IS function may need to examine the possibility of segmenting its user base to reflect this differing utility. The service task, i.e. definition of the 

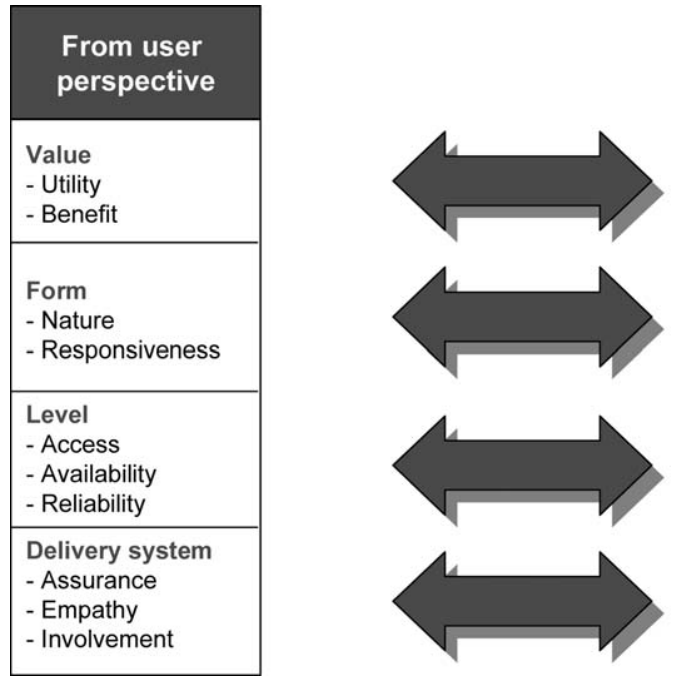

\begin{tabular}{l}
$\begin{array}{l}\text { From provider } \\
\text { perspective }\end{array}$ \\
\hline $\begin{array}{l}\text { Cost } \\
\text { User groups } \\
\text { Pricing policies }\end{array}$ \\
\hline Service task \\
Outputs \\
Metrics \\
\hline \begin{tabular}{l} 
Service \\
standards \\
Capacity mgmt \\
Access policies \\
\hline Process design \\
HR policies \\
Culture \\
Cl plans
\end{tabular} \\
\hline
\end{tabular}

Figure 9 Balancing User and Provider Perspectives. Provider Options are Illustrative Examples

service concept, may also be different for different communities of user. The value dimension can also influence charging mechanisms such as no billing for services, fixed price based on past usage or direct charging based on usage.

Form Depending on how form is defined by the user, the provider can then consider issues of service design and metrics.

Level The level of service guides pricing policies, access and availability policies and determines capacity requirements.

Delivery The definition of the delivery system system in terms of assurance, empathy and expected involvement of users provides guidance for process design, HR policies, and the culture that needs to be fostered.

In assessing the service, it may be that there are conflicts between the utility, form, level and the delivery system. For example, the definition of the form may position the service as a 'service factory' but the level of service may indicate that it is in the 'service boutique' category. These contrasting positions must therefore be reconciled by deciding on where the service is best positioned on the service process matrix and what dimension should be amended.

Let us look at an extreme example. Suppose the help desk is organised in the traditional way with users phoning through their problems. If the IS function is to respond immediately to users this has implications for resourcing. Reducing the service level to responding within 24 hours can mean that the workload is levelled out over the working day. The extra resources required in the former case are due to the 'lumpy' and predictable nature of the demand for service. If the help desk service is designed so as not to talk a user through the resolution process over the phone but rather respond personally to all service requests, this means that the service is now positioned in the service boutique quadrant. In this instance the service definition is different, delivery process is different, measurements might be different, the strategy for managing capacity will probably also be different. Interestingly, the utility of the service may not change; yet it is very likely that the cost of providing the service will increase.

Figure 10 presents a framework that brings together the discussion that has taken place in previous sections. The figure illustrates the relationship between investment and value and the mechanisms through which this value is created. The components of the framework have been introduced earlier in the paper.

It highlights that an organisation invests in a service through the acquisition of knowledge, skills, and resources, including technology, which are then deployed through effective resource allocation in organisational processes. These processes can be supported by technology, such as call-centre software that is often used by help desks to log calls, keep track of outstanding faults and provide a database to collect faults. The processes for information handling services are automated and enshrined in software systems. The performance of the service is to a large extent determined by the design of the delivery system, which includes not just process design but defines the role of both the user and provider. For most services, performance is ultimately judged by the user based on the nature and responsiveness of the service together with the availability, ease of access and reliability of the service.

This framework can be used in structuring and developing IST services. It also forms the basis for 


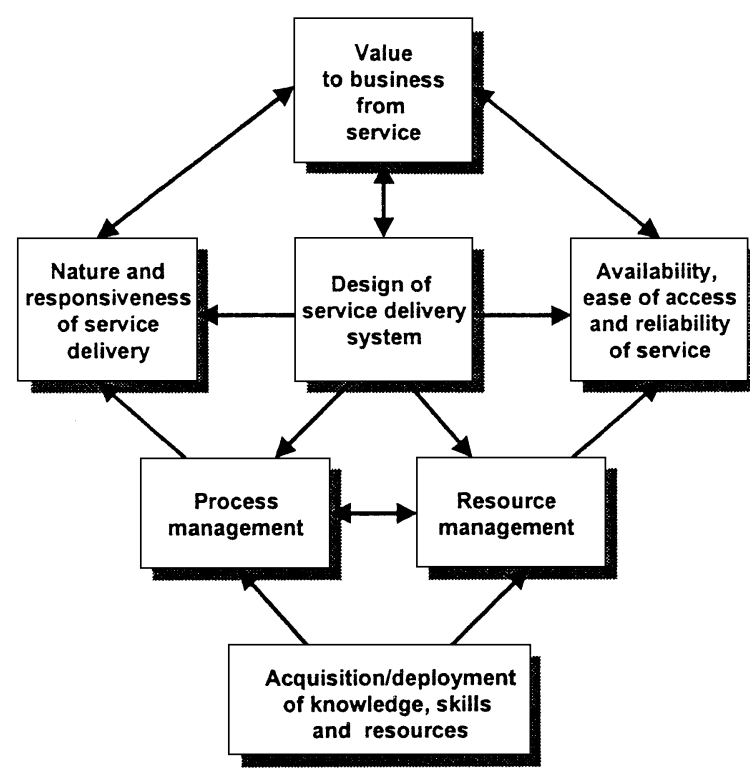

Value

Performance

Organisation

Cost/investment

Figure 10 An Overall Framework for IST Service Management

measuring the service components in terms of performance to specification and perceived performance as assessed by the users. It does, of course, rely on being able to define the value of the service, which as we have seen, can be difficult to do. Often, this has to be in terms of the negative consequences of unavailability or under-performance, to justify the cost against failure of the business to operate "normally'.

\section{Conclusions}

The role of the IS function has undergone a significant metamorphosis since the first computers found their way into organisations. It is no longer concerned with merely providing and maintaining the technologies to support the operations of the business. This wider remit means that the traditional notion of an IS function and its role and purpose are obsolete. The increasing dependence of organisations on their IT systems, the growing trend towards outsourcing and the increasing sophistication and demanding expectations of users has meant that managing the services in and around the processing, provisioning and stewardship of information has become paramount. Few organisations have managed to address this service dimension and fewer still are equipped with the requisite competencies and service culture that is necessary.

In this paper we have adopted a service perspective of IT and concerned ourselves with the management of all services in and around the processing, provisioning and stewardship of information. Yet users have a key role to play in the successful delivery of many IST services. Even with outsourcing, this role cannot be abdicated, a fact that is usually overlooked.
Organisations today usually have a strategy for application services, usually referred to as the IS strategy. But as we have illustrated there are many other services required to ensure that these application services are made available. Few organisations articulate a strategy for these IST services and this is an area requiring further research.

This paper has suggested that managing IT as a portfolio of services can help in achieving the necessary focus to deliver business value from IT investments. As users are required to play a role in the execution of services in and around the processing, provisioning and stewardship of information, the concluding analysis is that the IT organisation is the organisation, and not a separate function. Consequently, new organisational models and structures are needed.

\section{Notes}

1. In this paper users refer to those using the service. These can be at all levels in the organisation.

2. ITIL is the IT Infrastructure Library and part of the services provided by the UK's Office for Government Commerce (OGC). See BSI, 1999).

3. Some scholars, such as Weill and colleagues, see infrastructure as including a 'human' aspect. In our categorisation, these human aspects would be catagorised under valueenabling services or operational services. See Weill et al., 2002).

4. For third party vendors and external service providers (ESPs), the service being provided is the 'product', and is the prime source of revenue and therefore should be treated as such.

5. This framework is usually applied at an industry level with organisations choosing to position themselves in a particular quadrant. For example, the delivery processes of McDonalds are different than those of a high-class French restaurant; or a full-service broker has different delivery processes than an execution-only broker. 


\section{References}

Albrecht, K. (1988) At America's Service. Dow-Jones Irwin, Homewood, IL.

BSI (1999) A Code of Practice for IS Service Management. British Standards Institute, London.

Davis, T.R.V. (1993) Managing internal service delivery in organizations. In Advances in Service Marketing and Management Vol. 2, pp. 301-320. JAI Press,

Garvan, D. (1984) What does product quality mean? Sloan Management Review Fall.

Gronroos, C. (1986) From scientific management to service management: a management perspective for the age of service competition. International Journal of Service Industry Management 5(1), 5-20.

Grover, V., Cheon, M.J. and Teng, J.T.C. (1996) The effect of service quality and partnership on the outsourcing of information systems functions. Journal of Management Information Systems 12(4), 89-116.

Hays, R.D. (1997) Building an information technology service culture. Information Strategy: The Executive's Journal 14(1), 19-23.

Kohlemeyer III, J.M. and Blanton, J.E. (2000) Improving service quality. Journal of Information Technology Theory $\mathcal{E}$ Application 2(1).

Parasuraman, A., Zeithaml, V.A. and Berry, L.L. (1988) SERVQUAL: a multiple item scale for measuring consumer perceptions of service quality. Journal of Retailing 64(1), 12-40.

Pitt, L.F., Watson, R.T. and Kavan, C.B. (1995) Service quality:

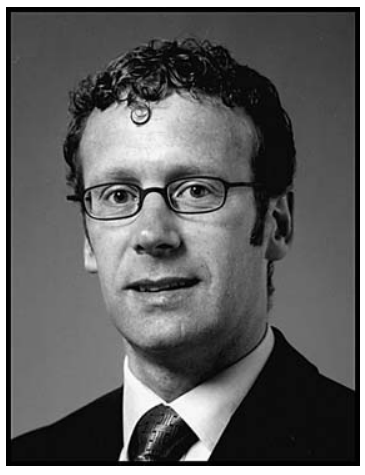

JOE PEPPARD, Information Systems Research Centre, Cranfield University School of Management, Cranfield, Bedford MK43 OAL. E-mail: j.peppard@ cranfield.ac.uk

Joe Peppard is Senior Research Fellow at the Information Systems Research Centre at Cranfield School of Management, and Director of Finlos Corporation, a software solutions provider to the financial services sector. His current work focuses on supporting organisations in the creation of value through IT investments and how hi-tech companies harness knowledge. a measure of information systems effectiveness. MIS Quarterly June, 173-185.

Pitt, L., Berthon, P. and Lane, N. (1998) Gaps within the IS department: barriers to service quality. Journal of Information Technology 13, 191-200.

Rands, T. (1992) Information technology as a service operation. Journal of Information Technology 7(4), 189-201.

Schmenner, R.W. (1995) Service Operations Management. Prentice-Hall, Englewood Cliffs, NJ.

Sylvestro, R., Fitzgerald, L., Johnston, R. and Voss, C. (1992) Towards a classification of service processes. International Journal of Service Industries Management 3(3).

Van Dyke, T.P., Kappelman, L.A. and Prybutok, V.R. (1997) Measuring information systems service quality: concerns on the use of SERVQUAL questionnaire. MIS Quarterly 21(2), 195-208.

Weill, P., Subramani, M. and Broadbent, M. (2002) Building IT infrastructure for strategic agility. MIT Sloan Management Review Fall, 57-65.

Whyte, G., Bytheway, A. and Edwards, C. (1997) Understanding user perceptions of information systems success. Journal of Strategic Information Systems 6, 35-68.

Willcocks, L.P. and Lacity, M.C. (1998) Introduction - the sourcing and outsourcing of IS: shock of the new. In Strategic Sourcing of Information Systems, eds L.P. Willcocks and M.C. Lacity, pp. 1-41. John Wiley \& Sons, Chichester.

Woodruff, R.B. (1997) Customer value: the next source of competitive advantage. Journal of the Academy of Marketing Science 25(2), 139-153. 